\title{
Effects of AIR pollution on cardiopuLmonary disEaSe in urban and peri-urban reSidents in Beijing: protocol for the AIRLESS study
}

\author{
Yiqun Han ${ }^{1,2}$, Wu Chen ${ }^{1}$, Lia Chatzidiakou ${ }^{3}$, Anika Krause ${ }^{3}$, Li Yan ${ }^{2}$, Hanbin Zhang ${ }^{2}$, Queenie Chan $^{2,4}$, \\ Ben Barratt ${ }^{2}$, Rod Jones ${ }^{3}$, Jing Liu ${ }^{5}$, Yangfeng Wu ${ }^{6,7}$, Meiping Zhao ${ }^{8}$, Junfeng Zhang ${ }^{9}$, Frank J. Kelly ${ }^{2}$, Tong Zhu ${ }^{1}$, \\ and the AIRLESS team+ \\ ${ }^{1}$ BIC-ESAT and SKL-ESPC, College of Environmental Sciences and Engineering, Peking University, Beijing 100871, China \\ ${ }^{2}$ Environmental Research Group, MRC Centre for Environment and Health, \\ Imperial College London, London, UK \\ ${ }^{3}$ Centre for Atmospheric Science, Department of Chemistry, University of Cambridge, Cambridge, UK \\ ${ }^{4}$ Department of Epidemiology and Biostatistics, MRC Centre for Environment and Health, \\ Imperial College London, London, UK \\ ${ }^{5}$ Department of Epidemiology, Beijing Anzhen Hospital, Capital Medical University, Beijing Institute of Heart, \\ Lung and Blood Vessel Diseases, Beijing, China \\ ${ }^{6}$ Peking University Clinical Research Institute, Beijing, China \\ ${ }^{7}$ The George Institute for Global Health at Peking University Health Science Center, Beijing, China \\ ${ }^{8}$ College of Chemistry, Peking University, Beijing, China \\ ${ }^{9}$ Duke Global Health Institute, Duke Kunshan University, Nanjing, China

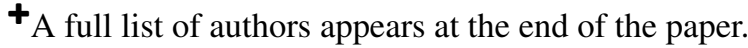

Correspondence: Tong Zhu (tzhu@pku.edu.cn) and Frank Kelly (f.kelly@imperial.ac.uk)

Received: 3 March 2020 - Discussion started: 23 March 2020

Revised: 16 September 2020 - Accepted: 10 October 2020 - Published: 18 December 2020

\begin{abstract}
Beijing, as a representative megacity in China, is experiencing some of the most severe air pollution episodes in the world, and its fast urbanization has led to substantial urban and peri-urban disparities in both health status and air quality. Uncertainties remain regarding the possible causal links between individual air pollutants and health outcomes, with spatial comparative investigations of these links lacking, particularly in developing megacities. In light of this challenge, Effects of AIR pollution on cardiopuLmonary disEaSe in urban and peri-urban reSidents in Beijing (AIRLESS) was initiated, with the aim of addressing the complex issue of relating multi-pollutant exposure to cardiopulmonary outcomes. This paper presents the novel methodological framework employed in the project, namely (1) the deployment of two panel studies from established cohorts in urban and peri-urban Beijing, with different exposure settings regarding pollution levels and diverse sources; (2) the collection of detailed measurements and biomarkers of participants from a nested case (hypertensive) and control (healthy) study set-
\end{abstract}

ting; (3) the assessment of indoor and personal exposure to multiple gaseous pollutants and particulate matter at unprecedented spatial and temporal resolution with validated novel sensor technologies; (4) the assessment of ambient air pollution levels in a large-scale field campaign, particularly the chemical composition of particulate matter. Preliminary results showed that there is a large difference between ambient and personal air pollution levels, and the differences varied between seasons and locations. These large differences were reflected on the different health responses between the two panels.

\section{Background}

Air pollution has been widely recognized as a major risk factor for human health, especially for cardiopulmonary morbidity and mortality. According to the Global Burden of Disease (GBD) study, exposure to ambient particulate matter of 
aerodynamic diameter $\leq 2.5 \mu \mathrm{m}\left(\mathrm{PM}_{2.5}\right)$ contributed to more than 4 million premature deaths worldwide annually, with China suffering the greatest health burden (1.08 million attributed deaths) (WHO, 2017). Chinese megacities, including Beijing, and their surrounding areas have high population densities and some of the highest air pollution concentrations in the world (Kelly and Zhu, 2016; Parrish and Zhu, 2009), with $\mathrm{PM}_{2.5}$ concentrations regularly exceeding World Health Organization air quality guidelines (Liu et al., 2016). However, the disease burden estimates in China are based almost entirely on epidemiological studies undertaken in Europe and North America, where concentrations and mixtures of air pollution in urban settings are likely to differ considerably between western and Chinese cities. It is unclear if health risks relating to poor air quality can simply be transcribed from one setting to the other (Burnett et al., 2014).

The rapid urbanization process, especially in some Chinese megacities, such as Beijing, has resulted in substantial urban and peri-urban disparities. This is reflected not only in health status due to differences in social economics and health services (Li et al., 2016), but also in the spatial contrast in air pollution in the greater Beijing area (Zhao et al., 2009; Wu et al., 2018; Xu et al., 2011). These contrasts in air pollution are partly driven by the variation in energy use (e.g. in winter, urban areas are dominated by centralized gas heating systems, while traditional biomass and coal stoves remain the key emission source for heating and cooking in peri-urban areas) and provide a unique opportunity to investigate their health impacts on local residents. Such comparative targeted investigations are however largely lacking to date, especially in rapidly developing countries such as China.

In light of these concerns, a consortium of UK and Chinese researchers developed Air Pollution and Human Health in a Chinese megacity Research Programme (APHH) (Shi et al., 2019). APHH includes four complementary research themes: (I) sources and emissions of urban atmospheric pollution, (II) processes affecting urban atmospheric pollution, (III) air pollution and health, and (IV) interventions and solutions. AIRLESS ("Effects of AIR pollution on cardiopuLmonary disEaSe in urban and peri-urban reSidents in Beijing") is nested within theme III of the APHH programme.

Based on two established cohorts in the urban and periurban area of greater Beijing, AIRLESS recruited two panels of non-smoking participants and completed four repeated follow-up clinical measurements during winter (2016) and summer (2017). Within the APHH programme, AIRLESS brings together a detailed integrated database of ambient, personal, and indoor measurements of a wide range of air pollutants and biomarkers, providing an unprecedented opportunity to test a variety of hypotheses on the adverse cardiopulmonary and metabolic effects of air pollution. Using these, the AIRLESS project is addressing several important research gaps that have been challenging to tackle due to methodological limitations of conventional air pollution epidemiology, as listed below. a. Investigate the susceptibility of hypertensive individuals to the adverse effect of air pollution.

Hypertension and air pollution are the third and fourth leading risk factors of mortality in China (WHO, 2017). More specifically, age-specific hypertension prevalence in China is reported as being $13.0 \%, 36.7 \%$, and $56.5 \%$ among persons aged $20-44,45-64$, and $\geq 65$ years, respectively (Gao et al., 2013). Air pollution, including household air pollution (HAP) from traditional biomass and coal stoves, is also acknowledged to be a strong determinant of blood pressure (Brook et al., 2010), supporting a hypothesis that air pollution directly and indirectly via hypertension has detrimental effects on human health. However, the interactive effects of hypertension and air pollution remain unclear (Sacks et al., 2011). AIRLESS aims to investigate this hypothesis using panel study design among participants with and without hypertension.

b. Establish reliable links between air pollution and health effects by reducing exposure misclassification.

Measurement of ambient air pollutants based on ground site observations and outputs from satellite and chemical transport models are often used as a proxy for personal exposure in epidemiological studies. However, accumulating evidence indicates that personal levels are poorly correlated with ambient levels due to variations of local sources, microenvironmental settings, and individual behavioural activities (Chatzidiakou et al., 2020). The difference between true exposure levels and ambient measurement is referred to as exposure misclassification, which might be larger in peri-urban areas where infrastructures are sparse and high levels of household air pollution (HAP) are common, thus biassing the estimation of exposure-response relationships (Steinle et al., 2013). AIRLESS takes advantage of the rapid advancement in low-cost sensors to provide highly resolved, validated personal exposure metrics (Chatzidiakou et al., 2019).

c. Differentiate source-related health effects of air pollution.

Humans are exposed to a complex mixture of gaseous and particulate pollutants emitted from a range of sources and/or arising from different chemical reactions. Although epidemiological studies worldwide have reported associations between reduced cardiorespiratory health and increased concentrations of air pollutants, such as particulate matter $(\mathrm{PM})$, ozone $\left(\mathrm{O}_{3}\right)$, and nitrogen dioxide $\left(\mathrm{NO}_{2}\right)$ (Brunekreef and Holgate, 2002; Shah et al., 2013), it is impossible to differentiate the health impacts of species highly correlated in the outdoor environment due to similar sources (i.e. $\mathrm{NO}_{2}$ and $\mathrm{PM}_{2.5}$ both primarily emitted from traffic). Additionally, PM (or other source-related mixtures) pro- 
duced by different sources may have different chemical compositions that would affect their toxicity (Kelly and Fussell, 2012). Research to date is yet to clearly define the differential toxicity of particle compositions, owing to the limited high-quality measurements of pollutant species applied in most epidemiological studies and often the high correlation between multiple pollutants (Han and Zhu, 2015). A further advantage of using detailed personal exposure measurements is that we can break the correlation between traffic-related pollutants (Chatzidiakou et al., 2020) to create reliable multipollutant health models that can identify causal links between sole pollutants and specific health responses.

d. Investigate the underlying mechanisms relating air pollution and health.

Although existing epidemiological evidence strongly supports a causal relationship between $\mathrm{PM}_{2.5}$ exposure and cardiopulmonary disease, gaps and uncertainties exist in our understanding of why and how this happens and what the implications may be for air pollution control (Brook et al., 2010). A number of pathways, such as oxidative stress (Lin et al., 2015; Gong et al., 2014), respiratory and systemic inflammation (Han et al., 2016; Lin et al., 2011), autonomic imbalance, and vascular dysfunction (Huang et al., 2012) have been suggested as mediators of the cardiopulmonary effects of air pollution. AIRLESS is one of the few human studies that has undertaken thorough examinations of the wide range of biomarkers to investigate the underlying mechanisms (Rajagopalan and Brook, 2012; Brook et al., 2010; Brook and Rajagopalan, 2009).

\section{Methods and design}

\subsection{Aims and objectives}

The overall aim of the AIRLESS project is to investigate the associations between exposure to multiple air pollutants and changes in health outcomes, with a focus on cardiopulmonary biomarkers in urban and peri-urban residents in Beijing. The specific objectives are as follows:

- to recruit two panels, each comprising of 120 participants from existing cohorts in urban and peri-urban Beijing;

- to establish infrastructure at urban and peri-urban sites to measure meteorological parameters and gaseous and particulate pollutant concentrations, including detailed chemical composition and size-fractional particles using state-of-the-art instrumentation;

- to use novel personal air quality monitors (PAMs) and portable instruments to assess personal and residential exposure to key ambient and household air pollutants;

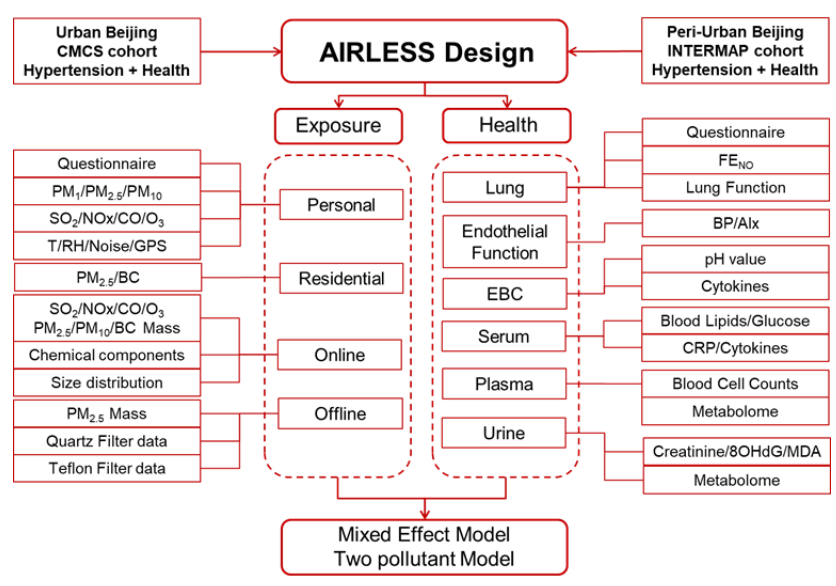

Figure 1. Design scheme of AIRLESS.

- to develop a time-activity-location model using parameters collected with the PAMs as inputs to investigate the frequency, duration, and magnitude of each participant's personal exposure to identify high-risk daily-life activities

- to assess cardiopulmonary health in the two panels;

- to quantitatively compare the air-pollution-associated health responses between urban and peri-urban areas and between hypertensive and healthy participants, across winter and summer seasons.

\subsection{Design and study population}

The AIRLESS study design is shown in Fig. 1. The project is designed as a panel study with repeated clinical measurements in both winter and summer seasons. Two panels of urban and peri-urban participants were recruited from two existing cohorts. Intensive ambient air pollution monitoring campaigns were launched simultaneously close to the participants' residences at two urban locations and one peri-urban location in Beijing during winter (7 November-21 December 2016) and summer field campaigns (22 May-21 June 2017). Detailed descriptions of the ambient air pollution monitoring campaign and clinic examinations are described in Sect. 2.3 to 2.7 .

The two existing cohorts approached to construct the AIRLESS panels are the Chinese Multi-provincial Cohort Study (CMCS) (Liu et al., 2004) from urban Beijing and the International Population Study on Macronutrients and BP (INTERMAP; Yan et al., 2020) in peri-urban Beijing.

CMCS was initiated in 1992 with the inclusion of 30121 Chinese adults aged 35 to 64 years from 11 provinces in China. It was established with the aim to explore risk factors that contribute to chronic diseases' occurrence and progress, mainly focusing on cardiovascular and pulmonary diseases. One of the CMCS population samples resides 
within the communities scattered around Peking University (PKU) Hospital, which is located north-west of the 4th Ring Road of Beijing.

The INTERMAP study is an epidemiological investigation aiming to clarify the role of multiple dietary factors in the aetiology of high blood pressure levels prevailing among mostly middle-aged and older individuals. The cohort comprised 4680 men and women aged 40-59 years from 17 diverse population samples in China, Japan, UK, and United States, with one sample from Pinggu District, a peri-urban area to the eastern end of Beijing with agriculture as the main sector of the local economy. All Pinggu participants reside in a number of local villages. INTERMAP is one of a few cohorts in peri-urban China with historical records on the pattern of energy use (Carter et al., 2020). The breadth and depth of high-quality data in both cohorts provide an excellent complement to the new data and bio-samples collected in AIRLESS.

To re-enrol 120 participants from CMCS and 120 participants from INTERMAP, new infrastructure was established for the clinical examination of participants at the Peking University Hospital (urban site) and at Xibaidian Village, Pinggu (peri-urban site), which are about $70 \mathrm{~km}$ apart (Fig. 2).

Based on the latest follow-up records for both cohorts, the available sample size of participants during AIRLESS recruitment period was 1252 (CMCS) and 177 (INTERMAP). Screening criteria for participant recruitment included personal factors, such as age, smoking status, health condition, and residential address (Table 1). After screening, the number of potential participants who met recruitment criteria were 1252 and 88 at the urban and peri-urban sites, respectively. Because the number of eligible participants of INTERMAP was insufficient due to the high prevalence of smoking in the existing cohort, we recruited a further 90 nonsmoking participants from the surrounding villages that fit the same criteria. In total, the sample size of eligible participants from the peri-urban site was then 178. Potential participants were randomly contacted through telephone calls or face-to-face meetings to discuss the project and to make appointments for clinical examinations during the two intensive campaign periods. Final recruitment figures were 123 and 128 participants at the urban and peri-urban clinics respectively. A subgroup of 39 urban and 33 peri-urban participants were further selected for a pilot residential exposure monitoring deployment as described in Sect. 2.4. The detailed screening steps are shown in Fig. 3.

Upon recruitment, written informed consent was obtained from all participants prior to study commencement. The study protocol was approved by the Institutional Review Board of the Peking University Health Science Centre, China (IRB00001052-16028), and the College Research Ethics Committee of King's College London, UK (HR16/17-3901).

The following information was collected through a baseline questionnaire after enrolment:
- demographic information (e.g. gender, age, education, income)

- current and past domestic energy use patterns (e.g. types of fuels and stoves, frequency of cooking and heating stove use)

- building characteristics

- active and second-hand smoking history

- dietary habits (e.g. consumption of alcohol, coffee/tea, sugar beverage drinking, fried food, vegetables)

- sleep quality

- daily activity patterns (transportation, exercise, and potential exposure sources)

- major health conditions, events, and diagnoses of noncardiovascular outcomes since the original enrolment

- regular medication or supplement usage.

\subsection{Ambient exposure}

A comprehensive dataset of ambient pollution metrics was collected in both seasons as part of Theme I, II, and III (AIRLESS) of the APHH research programme (Shi et al., 2019). Urban measurements were performed at two existing air quality monitoring stations with historical air pollution data, and peri-urban measurements were obtained from a newly established monitoring site adjacent to the clinic in Pinggu District. The urban and peri-urban clinics were both less than $500 \mathrm{~m}$ away from the nearby monitoring station, and most participants' residential addresses were in close proximity to the sites. The details of the three fixed stations are as follows:

- Urban site PKU. One of the urban monitoring sites is on the roof of a six-floor building on the PKU campus, namely the Peking University Urban Atmosphere Environment Monitoring Station (PKUERS) (Wang et al., 2018a), which is located $500 \mathrm{~m}$ north of the 4th Ring Road (GPS coordinates: 39.990, 116.313).

- Urban site IAP. The second urban site is located at the Institute of Atmospheric Physics (IAP) (Sun et al., 2012), $11 \mathrm{~km}$ south-east of the PKU site (GPS coordinates: $39.976,116.378)$. A $325 \mathrm{~m}$ tall meteorological tower provided the opportunity for vertical measurements of air pollution.

- Peri-urban site. At peri-urban Beijing, new infrastructure was established for the intensive monitoring campaign at Xibaidian Village, Pinggu District, which is about $75 \mathrm{~km}$ north-east of the PKU site (GPS coordinates: 40.167, 117.047). Instruments were deployed on the roof of a one-storey building in the far north end of the village. 


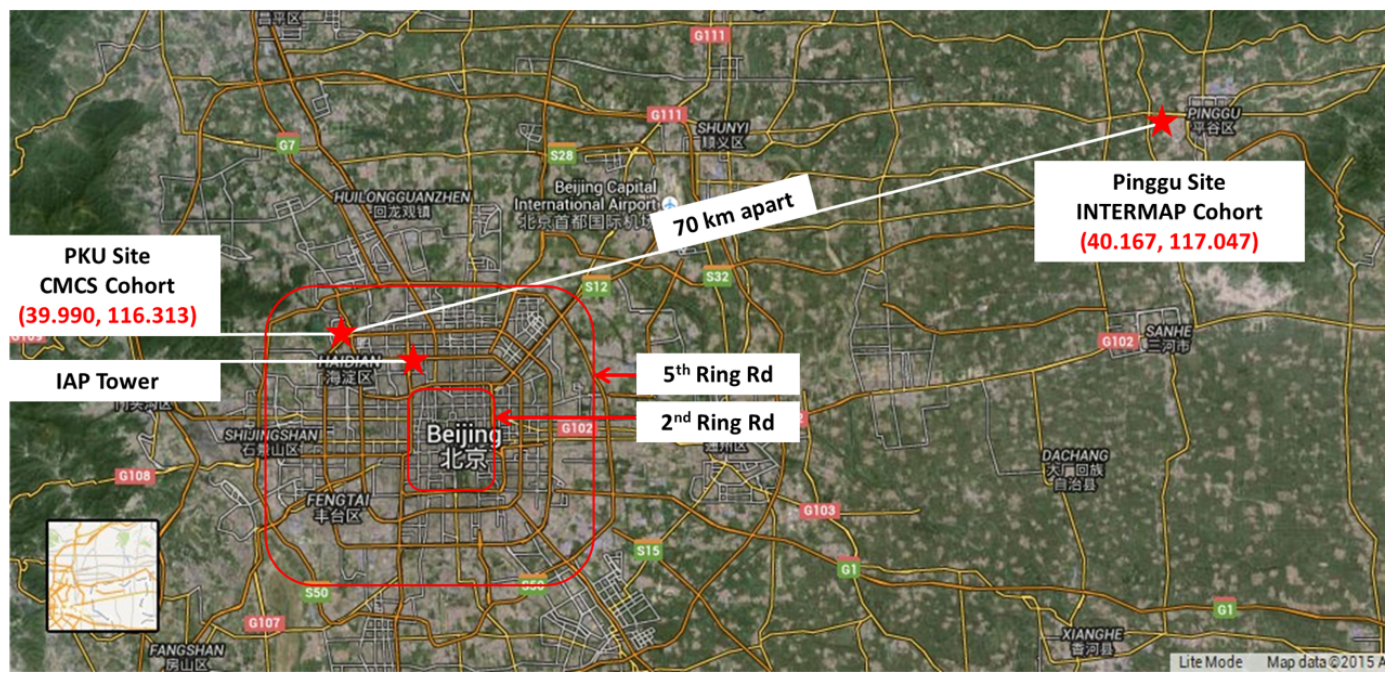

Figure 2. Locations of the two cohorts and three monitoring sites in urban and peri-urban Beijing. The figure is based on Google Maps (C) Google Maps.

Table 1. Recruitment criteria.

\begin{tabular}{l}
\hline Inclusion \\
\hline$-50 \leq$ age $\leq 75$ years \\
- Non-smokers or those who have quit smoking longer than 3 years ago \\
- Hypertensive participants (clinical diagnosis*) \\
- Healthy participants (clinical diagnosis*) \\
\hline Exclusion \\
\hline - Diagnosed with disease history of any cardiovascular or metabolic disease, including hyperlipidemia, malignant tumour, \\
coronary heart disease, cardiomyopathy, arrhythmia, stroke, hepatitis A/B, leukaemia, biliary calculus, thyroid nodule, \\
sick sinus syndrome or use of cardiac pacemaker, hyperthyroidism, hypothyroidism, multiple myeloma, rheumatoid arthritis, \\
pancreatitis, reflux esophagitis, thyroidectomy
\end{tabular}

* Clinical diagnosis: systolic blood pressure (SBP) $>=140 \mathrm{~mm} \mathrm{Hg}$ or diastolic blood pressure (DBP) $>=90 \mathrm{~mm} \mathrm{Hg}$ occurred in two repeated measurements.

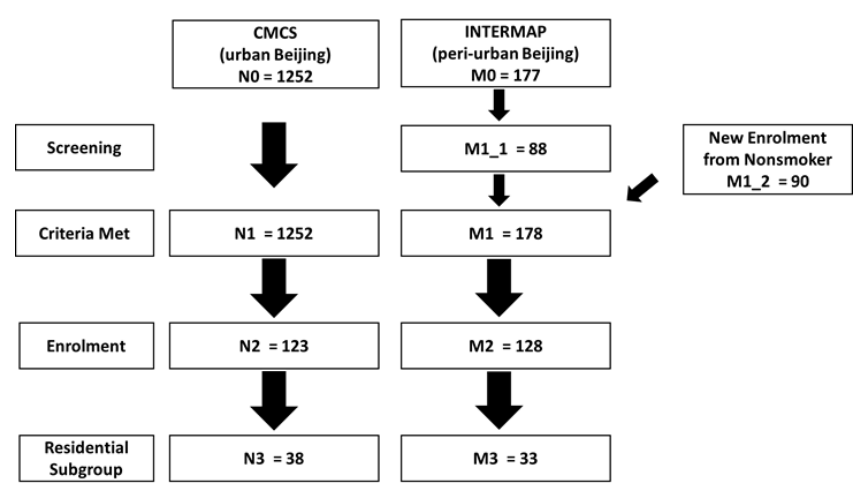

Figure 3. Screening steps for recruitment in AIRLESS. $\mathrm{N}$ refers to the sample size of CMCS cohort, and M refers to that of INTERMAP cohort; the number after letters $\mathrm{N}$ and $\mathrm{M}$ refers to the screening layer.
The same core instruments were deployed to all three sites (Table 2) with slight differences for certain pollutants between the sites. The collected measurements resulted in a comprehensive dataset of meteorological parameters, gaseous pollutants $\left(\mathrm{CO}, \mathrm{NO}_{x}, \mathrm{SO}_{2}\right.$, and $\left.\mathrm{O}_{3}\right)$, and physical and chemical properties of PM. Daily samples of $\mathrm{PM}_{2.5}$ (from 08:00 to 07:30 the next day) were collected on Teflon and quartz filters by medium- and high-volume samplers during the monitoring campaign periods and were analysed for elemental carbon (EC), organic carbon (OC), $\mathrm{SO}_{4}^{2-}, \mathrm{NO}_{3}^{-}$, $\mathrm{NH}_{4}^{+}, \mathrm{Na}^{+}, \mathrm{K}^{+}, \mathrm{Mg}^{2+}, \mathrm{Ca}^{2+}, \mathrm{F}^{-}, \mathrm{Cl}^{-}$, water-soluble organic compounds, and polycyclic aromatic hydrocarbons (PAHs) in the laboratory. Details of the instrumentation were elaborated in the APHH programme overview (Shi et al., 2019). 
Table 2. The matrix of exposure parameters in the AIRLESS study.

\begin{tabular}{|c|c|c|c|}
\hline Exposure index & Parameters & Method/instrument & Resolution \\
\hline \multicolumn{4}{|l|}{ Ambient exposure } \\
\hline \multirow[t]{9}{*}{ Particulate pollutants } & $\mathrm{PM}_{2.5}$ mass concentration & BAM(Pinggu)/TEOM 1400a (PKU) & Hourly \\
\hline & $\mathrm{BC}$ mass concentration & MAAP (Pinggu)/AE33 (PKU) & Hourly \\
\hline & Size distribution & SMPS & Hourly \\
\hline & Online EC/OC & Sunset & Hourly \\
\hline & Metal element & Xact & Hourly \\
\hline & NR chemical composition & ACSM/ToF-ACSM & Hourly \\
\hline & $\begin{array}{l}\text { Water-soluble ions } \\
\text { Water-soluble organic acid }\end{array}$ & $\begin{array}{l}\text { Dionex ICS-2500/2000 } \\
\text { Liquid chromatogram }\end{array}$ & Daily \\
\hline & Metal element & Thermo X series ICP-MS & Daily \\
\hline & PAHs & Agilent GC/MS & Daily \\
\hline \multirow[t]{4}{*}{ Gaseous pollutants } & $\mathrm{CO}$ & NDIR/Thermo Model 48i & Minute \\
\hline & $\mathrm{NO}_{x}$ & $\begin{array}{l}\text { Chemiluminescence/ } \\
\text { Thermo Model } 42 \mathrm{i}\end{array}$ & Minute \\
\hline & $\mathrm{SO}_{2}$ & Fluorescence/Thermo Model 43c & Minute \\
\hline & $\mathrm{O}_{3}$ & UV absorption/Thermo Model 49i & Minute \\
\hline $\begin{array}{l}\text { Meteorological } \\
\text { parameters }\end{array}$ & $\begin{array}{l}\text { Temperature, relative humidity, } \\
\text { barometric pressure, wind speed, } \\
\text { wind direction }\end{array}$ & Met One & Minute \\
\hline \multicolumn{4}{|l|}{ Personal exposure } \\
\hline Particulate pollutants & $\mathrm{PM}_{1}, \mathrm{PM}_{2.5}, \mathrm{PM}_{10}$ mass concentration & Optical particle counter (OPC) & $20 \mathrm{~s}$ \\
\hline Gaseous pollutants & $\mathrm{CO}, \mathrm{NO}, \mathrm{NO}_{2}, \mathrm{O}_{3}$ & Electrochemical sensors & $20 \mathrm{~s}$ \\
\hline \multirow{2}{*}{$\begin{array}{l}\text { Meteorological } \\
\text { parameters }\end{array}$} & Temperature & Thermocouple & $1 \mathrm{~min}$ \\
\hline & Relative humidity (RH) (\%) & Electrical resistive sensor & $1 \mathrm{~min}$ \\
\hline \multirow[t]{3}{*}{ Activity } & Spatial coordinates & Global Positioning System (GPS) & $1 \mathrm{~min}$ \\
\hline & Background noise & Microphone & $100 \mathrm{~Hz}$ \\
\hline & Physical activity & Tri-axial accelerometer & $100 \mathrm{~Hz}$ \\
\hline
\end{tabular}

\subsection{Residential exposure}

Residential exposure of subgroups from AIRLESS panels were measured during both winter and summer campaigns. At the urban site, measurements were conducted in the homes of participants $(N=39)$ who live within $100 \mathrm{~m}$ of the nearest main road. At the peri-urban site, a subgroup of participants $(N=33)$ were selected to be representative of the AIRLESS peri-urban panel regarding cooking and heating methods during winter. Residential exposure was measured only with residents' permission for home access and monitoring.

Two commercial portable real-time monitors, namely, a MA300/350 multi-wavelength aethalometer (Aethlabs,
USA) and MicroPEM v3.2 (RTI International, USA) were deployed for residential exposure measurements of black carbon and $\mathrm{PM}_{2.5}$. Instruments were co-located with reference monitors in Beijing before and after the fieldwork. Operation of the instruments followed a strict QA/QC method to ensure data quality. Monitoring instruments were installed in the room where the participant spent most of their time, with a consideration for noise tolerance of the residents. The monitoring period for each participant's home was between 3 and $4 \mathrm{~d}$ prior to one clinical measurement in each season. Home visits took place only on the day of clinical visits so that the disturbance to participants' normal lives could be minimized. 


\subsection{Personal exposure}

A key methodological strength of the AIRLESS project is the assessment of personal exposure to air pollution at a high spatial and temporal resolution. Taking advantage of recent advancements in sensor technology and computational techniques, a novel highly portable monitor $(\sim 400 \mathrm{~g})$ was developed at the University of Cambridge (Fig. S1) and has been successfully applied by a panel of participants in the UK for the adverse effects of personal exposure on chronic obstructive pulmonary disease (COPD) exacerbations (Moore et al., 2016). The PAM operates autonomously and continuously and is almost completely silent. It incorporates multiple low-cost sensors of physical and chemical parameters, as listed in Table 2. The PAM has a battery life of $24 \mathrm{~h}$ and can be charged on a designated base station. Measurements are recorded at 1 min time resolution and stored internally on a secure digital card. The data are then transmitted to a secure server when the PAM is returned to the base station for daily charging (Chatzidiakou et al., 2019).

The characterization of the performance of the air quality sensors integrated in the PAM is presented in a previous publication (Chatzidiakou et al., 2019). Briefly, all PAMs were calibrated in two outdoor co-location deployments at the urban PKU site next to reference instrumentation for 1 month after the winter and summer deployments to participants. The performance of the $\mathrm{NO}_{2}$ and $\mathrm{PM}_{2.5}$ sensors was additionally characterized in an indoor microenvironment next to commercial instruments. Overall, the air pollution sensors showed high reproducibility (mean $R^{2}=0.93$, min-max: 0.80-1.00) and excellent agreement with standard instrumentation $\left(R^{2}>0.84\right.$ for all sensors in winter, while $R^{2}>0.71$ in summer). Further work (Chatzidiakou et al., 2020) showed that the error of the PAM was negligible compared with the error introduced when deriving exposure metrics from fixed ambient monitoring stations close to the participants' residential addresses. Hence, novel sensing technologies such as the ones used here are suitable for collecting highly resolved personal exposure measurements in largescale health studies.

In total 60 devices were deployed at the urban and periurban clinic sites, which enabled the recruitment of 30 participants from each site each week (Fig. S1). The PAM was deployed in an easy-to-use carry case for protection, and each participant was instructed to carry the PAM for 1 week of their normal daily life. No other interference was required by the participants than to place it in the base station each night for charging and data transmission. Participants were informed that the monitors utilize GPS technology and were reassured that this information would not be accessed in real time but only used at the end of the study to analyse overall spatial and temporal relationships of fully anonymized data.

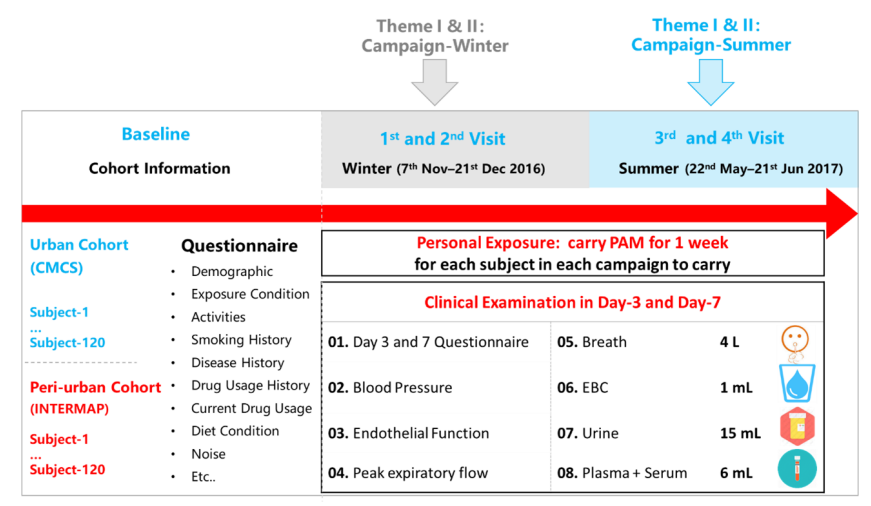

Figure 4. Scheme of clinical examination of AIRLESS.

\subsection{The time-activity-location model}

The collection of auxiliary parameters, such as timestamped geo-coordinated measurements, background noise, and accelerometer readings, enables the classification of timeactivity-location events with an automated algorithm. The algorithm is a progressive composite model that employs spatio-temporal clustering, rule-based models, and machine learning techniques. This enables the investigation of duration, frequency, and magnitude of personal exposure in different microenvironments in daily life and the estimation of activity-weighted exposure at the individual level, often used as a proxy for "dose" (Chatzidiakou et al., 2020). The classifications include core location categories ("home", "work", "other indoor static", "other outdoor static", "travel"), as well as activities ("cooking", "sleeping") and modes of transport ("walk", "cycle", "motorbike", "car/bus", "train/tube").

\subsection{Clinical examination}

Each participant was asked to complete a $7 \mathrm{~d}$ follow-up session in the winter and summer when the intensive air pollution measurement campaigns launched simultaneously (Fig. 4). Details of the clinical procedures and measurements are described below and listed in Table 3.

\subsubsection{At Day 0}

- Each participant was provided with a PAM and instructed to carry it with them during their daily activities and to keep it in the bedroom during night-time to obtain 1-week personal exposure measurements.

- Basic anthropometry measurements, such as weight, height, and hip and waist circumference, were obtained.

\subsubsection{At Day 3 and 7 (90 $\mathrm{min}$ in clinic)}

- Participants were asked to complete a follow-up questionnaire on their domestic fuel use, exposure, activities, 
Table 3. Measurement plans for health outcomes in AIRLESS study.

\begin{tabular}{|c|c|c|}
\hline Biological pathways & Sample/device & Health endpoints \\
\hline Blood pressure and heart rate & Omron HEM 907 & Systolic pressure, diastolic pressure, heart rate \\
\hline Endothelial function & Pulse wave analyser & AP/AIx/ED/SEVR \\
\hline \multirow[t]{4}{*}{ Respiratory inflammation } & Peak flow meter & $\mathrm{PEF}$ \\
\hline & Exhaled breath & $\mathrm{FE}_{\mathrm{NO}}$ \\
\hline & \multirow{2}{*}{$\mathrm{EBC}$} & $\mathrm{pH}$ \\
\hline & & Cytokines, e.g. IL- $1 \alpha$, IL- $1 \beta$, IL-2, IL-6, IL- 8, TNF $\alpha$, IFN- $\gamma$ \\
\hline \multirow[t]{3}{*}{ Cardiovascular inflammation } & \multirow{2}{*}{ Serum } & CRP \\
\hline & & Cytokines, e.g. IL- $1 \alpha$, IL- $1 \beta$, IL-2, IL-6, IL- 8, TNF $\alpha$, IFN- $\gamma$ \\
\hline & Plasma & WBCs, neutrophils, monocytes, lymphocytes \\
\hline \multirow[t]{3}{*}{ Metabolic } & \multirow{2}{*}{ Serum } & TG, HDL, LDL, cholesterol \\
\hline & & Glucose, insulin, HOMA-IR \\
\hline & Serum, urine & Untargeted/targeted metabolomic signatures \\
\hline \multirow[t]{2}{*}{ Oxidative stress } & Urine & MDA, creatinine \\
\hline & Plasma & DNA repair enzymes \\
\hline Genetic-related pathways & Blood & Genetic and epigenomic profiles \\
\hline
\end{tabular}

AP: augmentation pressure. AIx: augmentation index. EBC: exhaled breath condensate. PEF: peak expiratory flow. FE ${ }_{\mathrm{NO}}$ : fractional exhaled NO. IL: interleukin. IFN- $\gamma$ : interferon gamma. TNF $\alpha$ : tumour necrosis factor alpha. WBCs: white blood cells. CRP: C-reactive protein. TG: triglyceride. HDL: high-density lipoprotein. LDL: low-density lipoprotein. HOMA-IR: homeostatic model assessment of insulin resistance. MDA: malondialdehyde. ED: ejection duration. SEVR: subendocardial viability ratio.

medication use, and any sleep disturbance over the past $3 \mathrm{~d}$.

- Three consecutive measurements of brachial artery blood pressure were taken using a digital automatic blood pressure gauge for each participant in a sitting position after resting for $5 \mathrm{~min}$.

- Three consecutive measurements of vascular function were taken, including central (aortic) blood pressure, arterial stiffness parameters (augmentation pressure (AP), augmentation index (AI), ejection duration (ED), and the subendocardial viability ratio (SEVR)) for each participant in a supine position using a pulse wave analysis system developed by the Chinese Academy of Sciences (Zhang et al., 2012).

- Each participant was provided with a peak flow meter (Williams Medical, UK) and was instructed to perform three consecutive peak expiratory flow (PEF) measurements every morning during the participation week together with self-reported respiratory symptoms in a diary card.

- 4L of breath was collected in an aluminium airsampling bag. Exhaled $\mathrm{NO}\left(\mathrm{FE}_{\mathrm{NO}}\right)$ was measured with a chemiluminescence nitrogen oxide analyser (model 42i; Thermo Scientific) at a constant flow rate of $150 \mathrm{~mL} / \mathrm{s}$.
- $1 \mathrm{~mL}$ of exhaled breath condensate (EBC) was collected using a Jaeger EcoScreen collector (Erich Jaeger, Friedberg, Germany) and was used for analysis of $\mathrm{pH}$ values and inflammatory cytokines.

- Each participant was provided with a $15 \mathrm{~mL}$ polypropylene tube and was instructed to collect the midstream of their first morning urine sample.

- Before the blood sample, collection participants were asked to fast overnight $(>12 \mathrm{~h})$. All blood samples ( $2 \mathrm{~mL}$ plasma in EDTA-coated tube and $4 \mathrm{~mL}$ serum in uncoated glass tube) were collected by a nurse before 09:30 during the clinical visits.

Urine samples were stored at $-20^{\circ} \mathrm{C}$ and blood samples at $-80^{\circ} \mathrm{C}$ immediately after the collection or pre-treatment (such as centrifuge and sub-packing done in $2 \mathrm{~h}$ with samples placed on ice).

Counts of white blood cells (WBCs), neutrophils, monocytes, lymphocytes, red blood cells, and haemoglobin and platelets were measured immediately in the local clinic after blood collection. Levels of glucose-related parameters (fasting glucose, insulin, and homeostatic model assessment of insulin resistance (HOMA-IR)), lipid-related parameters (triglyceride (TG), high-density lipoprotein (HDL), low-density lipoprotein (LDL), and total cholesterol (Chol)), 
and C-reactive protein (CRP) were measured 1 month after the end of each campaign in the Anzhen Hospital in central Beijing. Further biochemical analyses included (1) multiple cytokines in EBC and the remaining blood samples, including interleukin 1 alpha (IL- $1 \alpha$ ), IL- $1 \beta$, IL-2, IL-6, IL-8, tumour necrosis factor alpha (TNF $\alpha$ ), and interferon gamma (IFN- $\gamma$ ); (2) concentrations of creatinine, malondialdehyde (MDA), and 8-hydroxydeoxyguanosine (8-OHdG) in urinary samples; (3) DNA repair enzymes in plasma samples; (4) high-throughput metabolomic analysis of both plasma and urine samples via gas chromatography-mass spectrometry (GC/MS) and liquid chromatography-mass spectrometry (LC/MS); and (5) genome-wide association studies, also planned for the second stage analysis, whereby genetic profiles and epigenomic data will be measured based on whole blood samples.

\subsection{Sample size and power calculations}

One of the main analyses in this study is the associations between air pollutants and the changes in multiple cardiopulmonary biomarkers. Based on a sample size of 240 participants, we examine the minimum detectable effect of $\mathrm{PM}_{2.5}$ on the four key health outcomes, namely systolic blood pressure (SBP), diastolic blood pressure (DBP), $\mathrm{FE}_{\mathrm{NO}}$, and WBCs, given the means and standard deviations (SDs) from previous studies (Dubowsky et al., 2006; Han et al., 2016; Jiang et al., 2014). Figure 5 and Table S1 show the minimum detectable effects in cross-sectional and longitudinal settings, with varying within-participant correlation coefficients. The results suggest the assumed sample size $(n=240)$ will provide adequate power to detect the changes in these four key cardiopulmonary outcomes that are in line with the findings in previous studies (Dvonch et al., 2009; Han et al., 2016; Dubowsky et al., 2006). For example, assuming a withinparticipant SD of $7.0 \mathrm{~mm} \mathrm{Hg}$ in SBP, for a SD increase in the level of exposure to $\mathrm{PM}_{2.5}$, a two-sided $\mathrm{F}$ test at a significance level of 0.05 with a $80 \%$ statistical power will be able to detect an increase of 1.25 unit in SBP in a cross-sectional setting and an increase of 0.53 and 0.34 unit in SBP in a longitudinal setting, with a within-participant correlation of 0.5 and 0.8 respectively.

\subsection{Statistical analysis}

In the AIRLESS project we aim to (1) examine the associations between multiple air pollutants and a wide range of cardiopulmonary changes; (2) compare the difference of biological changes in urban and peri-urban settings across seasons; (3) determine if these associations differ in potential susceptible participants, e.g. those with hypertension or other underlying cardiopulmonary disease.

A master database was built to link the data obtained from ambient, residential, and personal exposure to air pollutants, health outcomes, and baseline and follow-up question- naires. Mixed linear effect models with distributed lag structures will be applied to examine the associations between air pollutants and health outcomes. The model will include a single random intercept for participant and assumed equicorrelation between all observations assigned to each participant. Multiple variables will be controlled in the model, including age, sex, body mass index (BMI), smoking status, medication usage, history of diseases, and day of week. Temperature and relative humidity ( $\mathrm{RH}$ ) will also be adjusted with a non-linear function integrating specific parameters determined by the minimum of Akaike information criterion (AIC). We will estimate the changes in biomarker concentration associated with each interquartile range increase in pollutant concentrations in the $24 \mathrm{~h}$ before the clinic visit, as well as the previous $1-7 \mathrm{~d}$. To examine the effect of air pollutant on multiple biomarkers (e.g. metabolome and transcriptome), the false discovery rate (FDR) adjusted $p$ value will be applied to detect the statistical significance. Pathway enrichment analyses based on the changes in multiple biomarkers will be used to investigate potential mechanisms. To examine the difference of biological responses to ambient $\mathrm{PM}_{2.5}$ between urban and peri-urban residents and between potentially susceptible participants and healthy controls, the stratified effect will be estimated by adding an interactive term of exposure and categorical variables of the tested group in the model. All statistical analysis will be performed using R Statistical Software (https://www.r-project.org/, last access: 30 November 2020).

\section{Preliminary results}

\subsection{Demographics characteristics of urban and peri-urban participants}

We recruited 251 participants (urban $=123$, periurban $=128$ ), and 218 of these participants (urban $=102$, peri-urban $=116$ ) completed all four visits at the end of the summer campaign. In total, 938 person-times clinical visits were collected, and the response rate was $83 \%(102 / 123)$ and $91 \%(116 / 128)$ for re-enrolment in the summer campaign at urban and peri-urban sites respectively (Table 4). The number of hypertensive and healthy participants was 104 and 147 respectively, with a comparable ratio between the two sites ( $\chi^{2}$ test, $\left.p=0.16\right)$. The mean (SD) age of urban and peri-urban participants was 65.7 (4.4) years and 60.7 (5.5) years, respectively. The gender ratio was relatively balanced, with more females participating at both sites. Compared with peri-urban participants, urban residents had a lower BMI and a higher educational and income level at the baseline $(p<0.05)$. Most participants were non-smokers, with $24(19.5 \%)$ urban and $29(22.7 \%)$ peri-urban participants with a smoking history but who had quit at least 3 years ago. Peri-urban participants are 

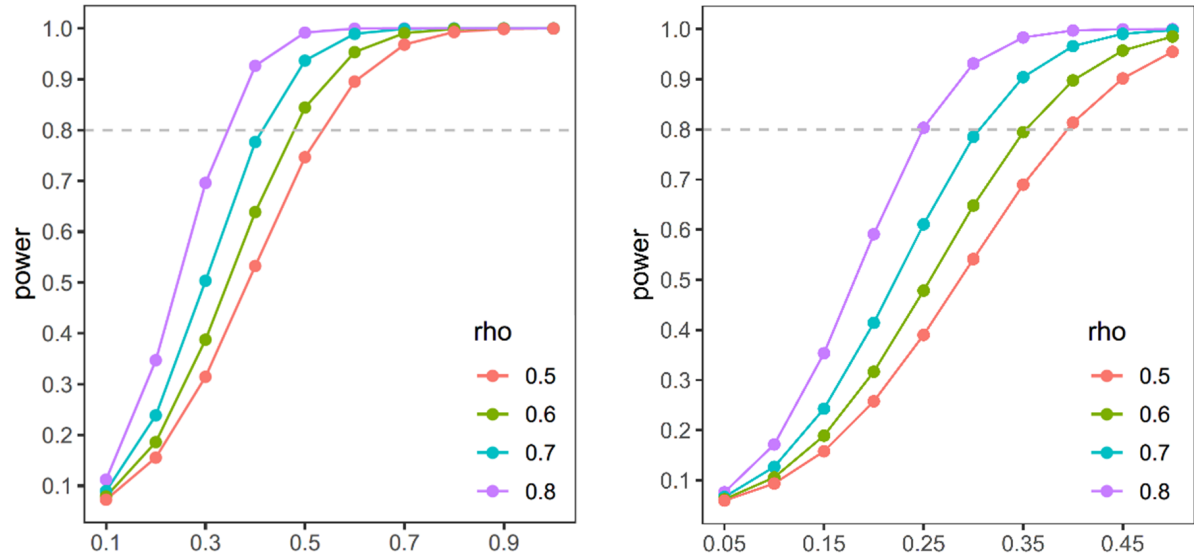

Exposure effect on SBP
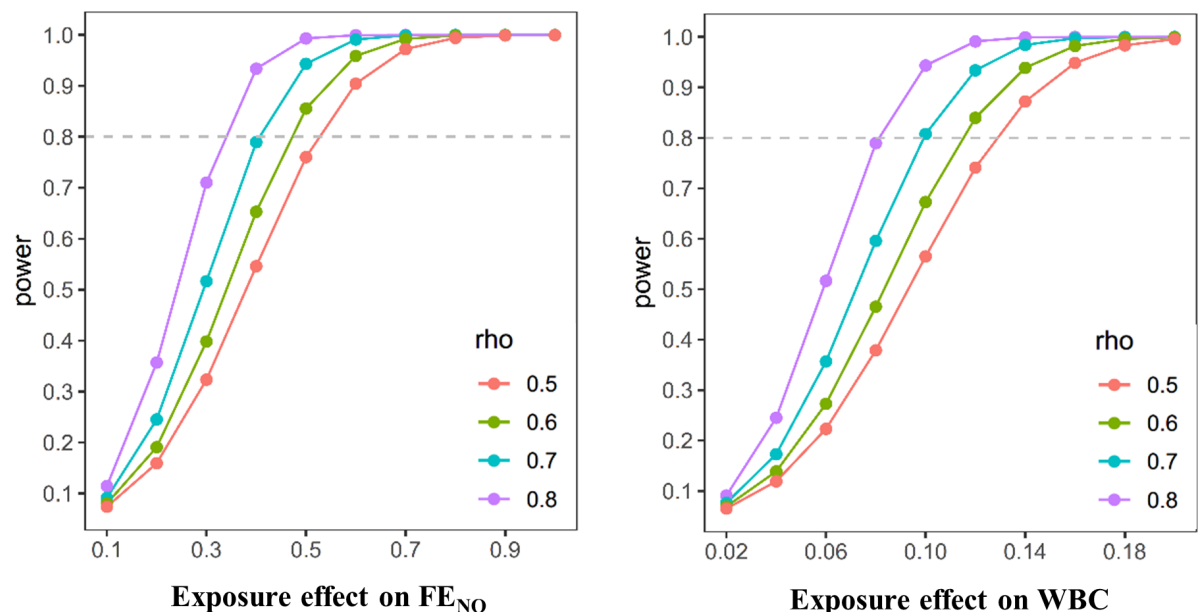

Exposure effect on WBC

Figure 5. Statistical power as functions of the detectable effect and covariance structure for cardiopulmonary outcomes. Power curves are calculated by using a sample size of 240, within-participant correlation coefficients (as denoted by rho) of 0.5 and 0.8 , and estimated SDs of 7.0, 5.2, 6.9, and 1.69 for outcomes SBP, DBP, FE $\mathrm{NO}$, and WBCs respectively. Changes in outcomes are reported with SD increase in exposure factor. SBP: systolic blood pressure; DBP: diastolic blood pressure; FE $\mathrm{NO}_{\mathrm{O}}$ : fractional exhaled NO; WBCs: white blood cells.

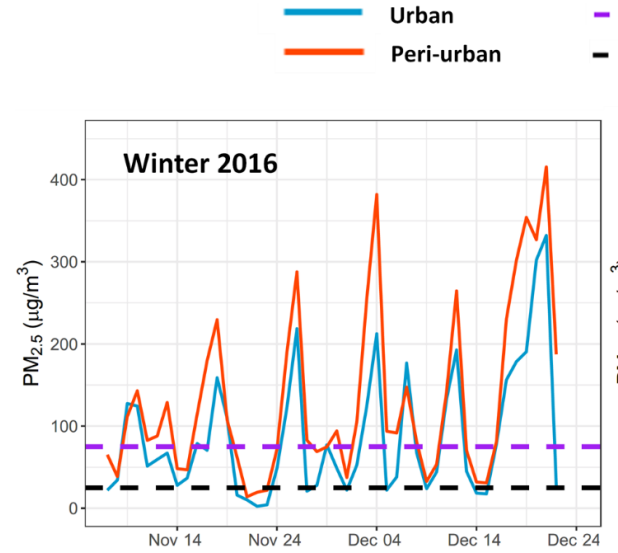

- China daily standard of $75 \mu \mathrm{g} / \mathrm{m}^{3}$

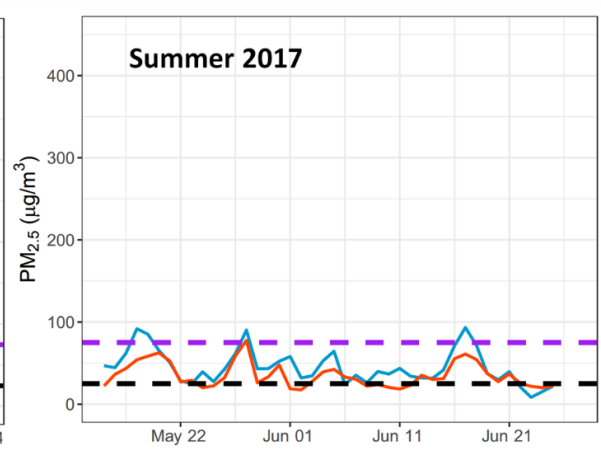

Figure 6. Seasonal and spatial trend of ambient $\mathrm{PM}_{2.5}$ concentration during AIRLESS campaigns. 
Table 4. Statistic summary of demographic characteristics of urban and peri-urban participants.

\begin{tabular}{|c|c|c|c|c|}
\hline & Unit & Urban & Peri-urban & $P$ value* \\
\hline Participant (winter) & $N$ & 123 & 128 & \\
\hline Participant (summer) & $N$ & 102 & 116 & \\
\hline Visit person-times & & & & \\
\hline All & $N$ & 450 & 488 & \\
\hline Winter & $N$ & 246 & 256 & \\
\hline Summer & $N$ & 204 & 232 & \\
\hline $\begin{array}{l}\text { Participants statistics } \\
\text { Continuous variables }\end{array}$ & \multicolumn{3}{|c|}{ Mean (standard deviation, SD) } & \\
\hline Age & Years & $65.7(4.4)$ & $60.7(5.5)$ & $<0.01$ \\
\hline BMI & $\mathrm{kg} / \mathrm{m}^{2}$ & $24.8(3.2)$ & $26.4(3.2)$ & $<0.01$ \\
\hline WHR & NA & $0.87(0.05)$ & $0.89(0.04)$ & $<0.01$ \\
\hline $\begin{array}{l}\text { Participants statistics } \\
\text { Categorical variables }\end{array}$ & \multicolumn{3}{|c|}{$N$ (percentage of total participants) } & \\
\hline \multicolumn{5}{|l|}{ Gender } \\
\hline $\begin{array}{l}\text { Male } \\
\text { Female }\end{array}$ & $\begin{array}{l}\text { No. }(\%) \\
\text { No. }(\%)\end{array}$ & $\begin{array}{l}58(47.2) \\
65(52.8)\end{array}$ & $\begin{array}{l}51(39.8) \\
77(60.2)\end{array}$ & 0.26 \\
\hline \multicolumn{5}{|l|}{ Education } \\
\hline $\begin{array}{l}\text { High school and below } \\
\text { College and above }\end{array}$ & $\begin{array}{l}\text { No. }(\%) \\
\text { No. }(\%)\end{array}$ & $\begin{array}{l}27(22.0) \\
96(78.0)\end{array}$ & $\begin{array}{r}28(100.0) \\
0(0.0) \\
\end{array}$ & $<0.01$ \\
\hline \multicolumn{5}{|l|}{ Annual income } \\
\hline $\begin{array}{l}<20000 \mathrm{RMB} \\
\geq 20000 \mathrm{RMB} \\
\mathrm{NA}\end{array}$ & $\begin{array}{l}\text { No. }(\%) \\
\text { No. }(\%) \\
\text { No. }(\%)\end{array}$ & $\begin{array}{r}8(6.5) \\
111(90.2) \\
4(3.3)\end{array}$ & $\begin{array}{r}67(52.3) \\
53(41.4) \\
8(6.2)\end{array}$ & $<0.01$ \\
\hline \multicolumn{5}{|l|}{ Smoking status } \\
\hline $\begin{array}{l}\text { Non-smoker } \\
\text { Past-smoker }\end{array}$ & $\begin{array}{l}\text { No. }(\%) \\
\text { No. }(\%)\end{array}$ & $\begin{array}{l}99(80.5) \\
24(19.5)\end{array}$ & $\begin{array}{l}99(77.3) \\
29(22.7)\end{array}$ & 0.63 \\
\hline \multicolumn{5}{|l|}{ Second-hand smoking* } \\
\hline $\begin{array}{l}\text { Never } \\
\text { Past } \\
\text { Now } \\
\text { NA }\end{array}$ & $\begin{array}{l}\text { No. }(\%) \\
\text { No. }(\%) \\
\text { No. }(\%) \\
\text { No. }(\%)\end{array}$ & $\begin{array}{r}73(59.3 \%) \\
30(24.4 \%) \\
19(15.4 \%) \\
1(0.8 \%)\end{array}$ & $\begin{array}{r}65(50.8 \%) \\
26(20.3 \%) \\
37(28.9 \%) \\
0(0 \%)\end{array}$ & $<0.05$ \\
\hline \multicolumn{5}{|l|}{ Cooking time } \\
\hline $\begin{array}{l}<1 \mathrm{~h} / \text { day } \\
>=1 \mathrm{~h} / \text { day } \\
\mathrm{NA}\end{array}$ & $\begin{array}{l}\text { No. }(\%) \\
\text { No. }(\%) \\
\text { No. }(\%)\end{array}$ & $\begin{array}{r}64(52.0 \%) \\
57(46.3 \%) \\
2(1.6 \%)\end{array}$ & $\begin{array}{r}48(37.5 \%) \\
79(61.7 \%) \\
1(0.8 \%)\end{array}$ & $<0.05$ \\
\hline \multicolumn{5}{|l|}{ Hypertension } \\
\hline $\begin{array}{l}\text { No } \\
\text { Yes }\end{array}$ & $\begin{array}{l}\text { No. }(\%) \\
\text { No. }(\%)\end{array}$ & $\begin{array}{l}66(53.7 \%) \\
57(46.3 \%)\end{array}$ & $\begin{array}{l}81(63.3 \%) \\
47(36.7 \%)\end{array}$ & 0.16 \\
\hline \multicolumn{5}{|l|}{ Hypertension medication } \\
\hline $\begin{array}{l}\text { No } \\
\text { Yes } \\
\text { NA }\end{array}$ & $\begin{array}{l}\text { No. }(\%) \\
\text { No. }(\%) \\
\text { No. }(\%)\end{array}$ & $\begin{array}{r}73(59.3 \%) \\
48(39.0 \%) \\
2(1.6 \%)\end{array}$ & $\begin{array}{r}80(62.5 \%) \\
43(33.6 \%) \\
5(3.9 \%)\end{array}$ & 0.53 \\
\hline
\end{tabular}

* The significance of difference between the urban and peri-urban participants and the $p$ value is determined based on Student's $t$ test and a chi-squared test for continuous and categorical variables, respectively. NA: not available. 


\section{Participation period}

(a)

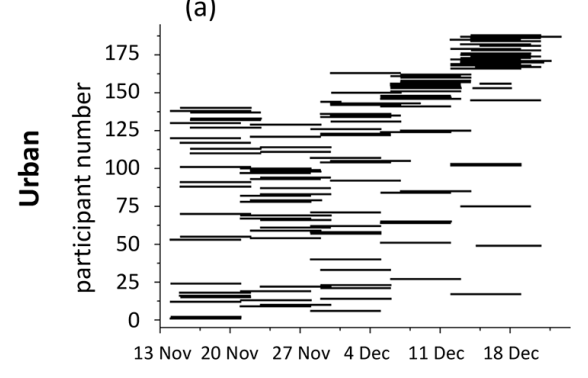

(b)

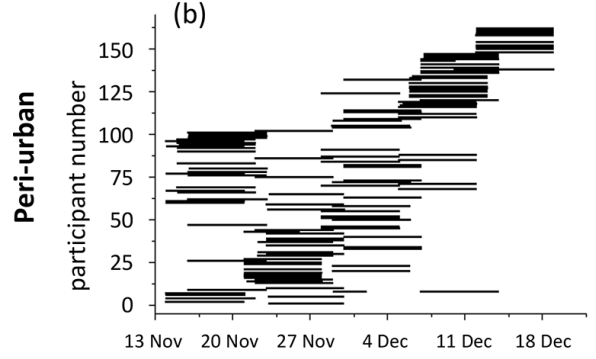

Personal data capture rate

(c)
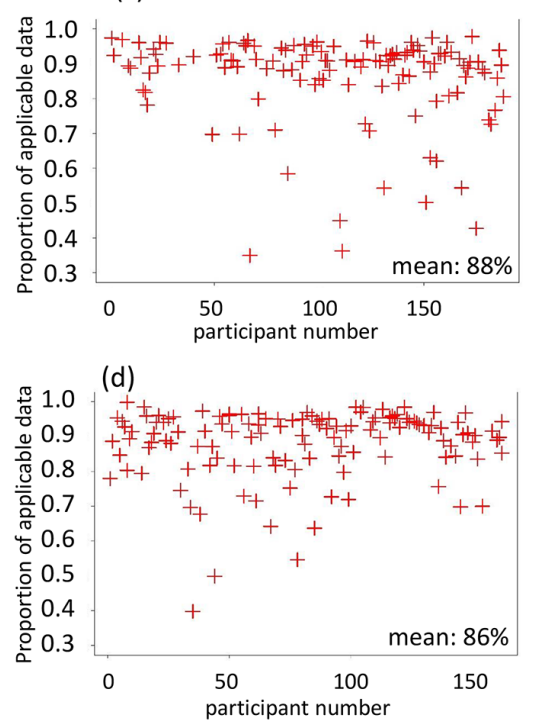

Covered area by all participants

(e)

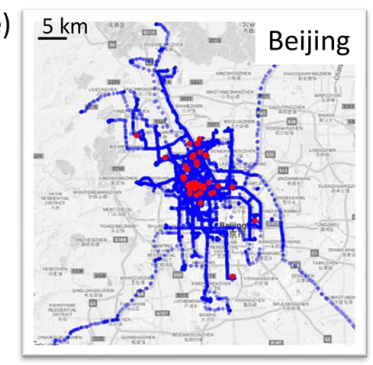

(f)

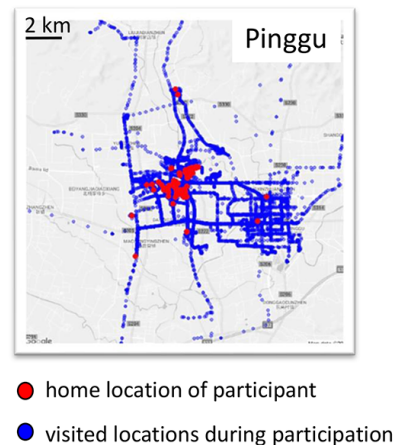

Figure 7. Participant compliance with the study protocol for personal exposure measurements during the winter season. Panels (a) and (b) show participant recruitment during the winter season at the urban and peri-urban sites. Each line represents start and end dates of an individual participant. Each week about 30 participants participated at each site. Panels (c) and (d) show personal data capture rate after appropriate data cleaning. At both sites we collected $>86 \%$ of theoretic observations. Panels (e) and (f) show GPS data of 251 participants carrying 60 PAMs plotted on urban and peri-urban maps (blue). Home locations (red) mined with the time-activity model. The figure is based on Google Maps (C) Google Maps.

more likely exposed to second-hand smoking and cooking scenarios than urban residents.

\subsection{Ambient concentration of $\mathbf{P M}_{2.5}$ during study periods}

Figure 6 shows the ambient $\mathrm{PM}_{2.5}$ concentration during AIRLESS campaigns in winter and summer with a comparison between sites. A clear seasonal trend with a large variation of ambient $\mathrm{PM}_{2.5}$ concentration was observed. Specifically, during winter, the mean (SD) daily concentrations were 132.3 (104.8) $\mathrm{\mu g} \mathrm{m}^{-3}$ and 87.4 (79.0) $\mathrm{\mu g} \mathrm{m}^{-3}$ at periurban and urban sites respectively, which were significantly higher than the corresponding concentrations in summer of 35.2 (15.0) and $45.1(20.8) \mu \mathrm{g} \mathrm{m}^{-3}$. The degraded ambient air quality and several high $\mathrm{PM}_{2.5}$ pollution events in winter were due to the greater stagnation and weak southerly circulation suggested by synoptic-scale meteorological analysis (Shi et al., 2019). The number of days with concentrations exceeding the Chinese standard of $75 \mu \mathrm{g} \mathrm{m}^{-3}$ was 29 and 19 during winter at peri-urban and urban sites respectively. The $\mathrm{PM}_{2.5}$ concentration in the urban area was constantly lower than the peri-urban site during winter, but the trend was opposite in summer.

\subsection{Completion of personal exposure during study periods}

Regarding personal exposure, participants completed 3548 personal days' measurements $(\sim 3.5$ million observations in $1 \mathrm{~min}$ time resolution). The participants showed high compliance with the protocol, with a mean capture rate of personal data of $>86 \%$ (Fig. 7c and d). The time-activity model showed that the peri-urban participants spent on average $90 \%$ of their time indoors at home and less than $2 \%$ of their time travelling (Chatzidiakou et al., 2020). The urban participants spent less time at home $(84 \%)$ and more time travelling (5\%) and covered a larger spatial area (Fig. 7e, f).

\subsection{An illustrative example of exposure misclassification}

A representative participant (U123) was selected to illustrate the concept of exposure misclassification in Fig. 8. Personal exposure measurements of participant U123 during the winter campaign are compared with data from the closest monitoring station to the participant's home location $(<5 \mathrm{~km})$. The time-activity model (Sect. 2.6) determined when the participant was located at home. The personal $\mathrm{CO}, \mathrm{NO}, \mathrm{NO}_{2}$, and $\mathrm{PM}_{2.5}$ concentrations regularly exceeded the outdoor levels, indicating that strong indoor emission sources (such 


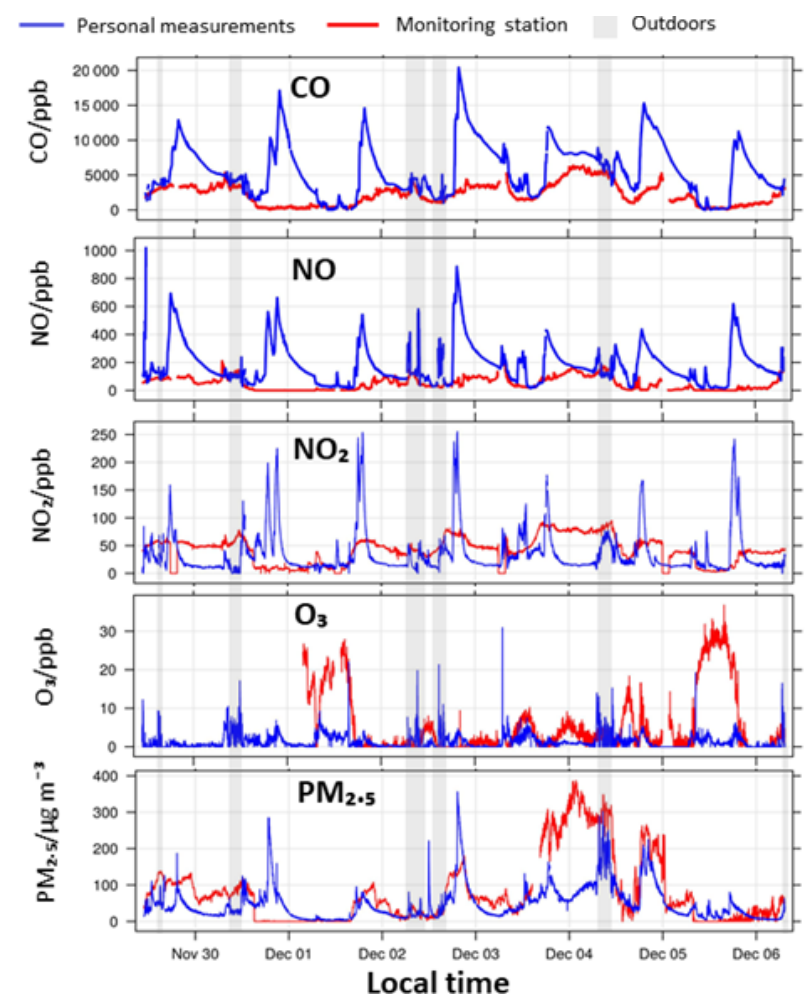

Figure 8. Time series of the air pollution exposure of participant U123 in the AIRLESS project (heating season). Personal exposure measurements (blue) are compared to data from the closest monitoring station to the participant's home (red). Grey and white areas indicate the participant is outdoors or at home respectively (based on time-activity model).

as a gas stove) operated at regular times. The sources caused personal exposure up to 10 times higher than the ambient pollution levels. When no emission sources were active, the indoor $\mathrm{CO}$ and $\mathrm{NO}$ concentrations approached the outdoor concentrations, whereas the $\mathrm{NO}_{2}, \mathrm{O}_{3}$, and $\mathrm{PM}_{2.5}$ were much lower than the outdoor concentrations, indicating the presence of indoor chemical sinks. In the case of ozone particularly, personal indoor exposure was up to 25 times lower than the ambient concentrations, due to the high indoor reactivity of the pollutant.

\subsection{Seasonal and spatial pattern of the difference between personal and ambient exposure}

The personal measurements show that there is a substantial exposure misclassification that could be introduced when using outdoor measurements as exposure metrics, particularly during the winter season. Overall, there were two distinctive profiles consistent between seasons: personal $\mathrm{CO}$ and NO levels were consistently higher than outdoor levels and showed a strong seasonal variation, with higher levels measured during the winter season. Conversely, $\mathrm{NO}_{2}, \mathrm{O}_{3}$, and $\mathrm{PM}_{2.5}$ were significantly lower than outdoor levels in both seasons and showed little $\left(\mathrm{PM}_{2.5}\right.$ and $\left.\mathrm{O}_{3}\right)$ or no $\left(\mathrm{NO}_{2}\right)$ seasonal variation (Chatzidiakou et al., 2020). Figure 9 shows that the difference between personal and outdoor $\mathrm{CO}$ concentrations was much higher during winter, particularly in the peri-urban panel, indicating stronger sources within close proximity to these participants. In contrast, personal $\mathrm{PM}_{2.5}$ was on average consistently lower than the ambient level at both sites, except for comparable levels at the rural site during the summer, possibly due to increased ventilation rates of the residents.

\section{Discussion}

China has undergone rapid transitions with regard to both air quality and public health in the last 3 decades. Driven by fast urbanization, metropolitan cities such as Beijing manifest a unique difference between urban and peri-urban areas regarding both health status ( $\mathrm{Li}$ et al., 2016) and varying air pollution concentrations with diverse chemical composition (Zhao et al., 2009; Wu et al., 2018; Xu et al., 2011), which may, in part, be responsible for the different health responses of local residents. The burden of public health in China has also seen a marked decline in child mortality and infectious diseases, while cardiovascular disease (CVD) has emerged as the leading cause of death (Yang et al., 2013). Hypertension, as the leading risk factor of CVD in China, was reported with a prevalence of $23.4 \%$ and $23.1 \%$ in urban and rural residents in Chinese adults respectively (Wang et al., 2018b). Many studies investigated the association between short-term PM exposure and CVD-related outcomes in stratified analysis; however, it remains unclear whether hypertension is a significant modification factor (Sacks et al., 2011).

Given the severe air pollution and nationwide hypertension epidemic in China, AIRLESS sets to (a) investigate the interactive effects of air pollution and hypertension, (b) establish more reliable links between air pollution and health effects by reducing exposure misclassification, (c) differentiate source-related health effects of air pollution, and (d) investigate the underlying mechanisms relating air pollution and health. Several novel methodological elements strengthen the design of the AIRLESS study.

Firstly, the study deployed a state-of-the-art and validated PAM to improve the personal exposure assessment to multiple pollutants. The high compliance rate of the participants with the study protocol highlighted the feasibility of collecting personal exposure data at high spatio-temporal resolution matched with detailed health assessments. The preliminary results highlight a clear difference between personal and ambient exposure driven by individual activity patterns, meteorological factors, and the built environment. In line with previous literature, we show the large biases arising from the use of ambient measurements to represent personal exposure in most epidemiological studies and the potential of novel sensor technologies to revolutionize future human-based studies. 

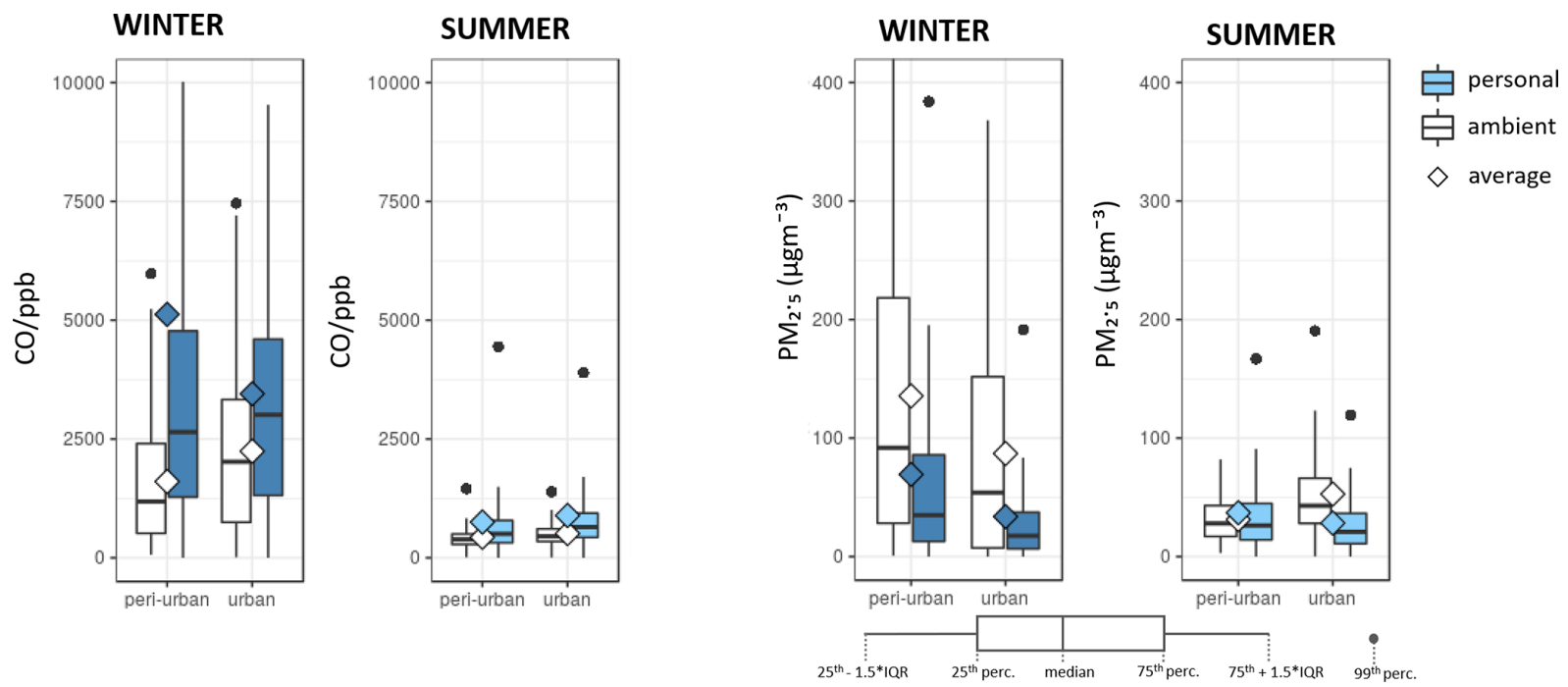

Figure 9. Box plots of ambient and personal air pollution levels in urban and peri-urban Beijing during the winter and summer campaigns. The white whisker box plots illustrate outdoor air pollution levels measured at the reference monitoring stations during the winter and summer campaigns. The blue box plots show the levels measured with 60 PAMs (dark and light blue for winter and summer respectively) deployed to 251 participants during the same periods. IQR: interquartile range; perc: percentile.

Secondly, time-activity-location patterns of individuals are important determinants of personal exposure, but due to the relative difficulty of collecting such information, they have rarely been taken into account in air pollution epidemiology. For the relatively sedentary participants of this panel study, the home environment was the major contributor to overall exposure and an important modifier of personal concentrations for all investigated air pollutant species. Exposure differences between the two panels were attributed partly to the variation in domestic energy use. For instance, in winter the urban building stock in China relies on centralized gas heating systems, while traditional biomass and coal stoves remain the key emission source for heating and cooking in peri-urban areas. However, the exposure variability between participants was larger than the variability between the two groups, stressing the need to go beyond current methodologies to estimate population exposure.

Lastly, panel studies might be the most suitable way to link intensive air monitoring campaigns for a wide range of pollutant species and personal exposure in different microenvironments, together with epidemiological studies of detailed biological changes in humans. Taking advantage of the simultaneously launched air monitoring campaigns, we successfully collected a rich set of data regarding both exposure and health outcomes. This provides a rare opportunity to investigate the effect of different pollutant species and the underlying biological pathways.

Altogether, the forthcoming outcomes of the AIRLESS project will enhance our understanding of the impact of environmental exposure on human health in a megacity and reinforce evidence-based policies at the appropriate scale that in turn may greatly improve the health and quality of life of China's ageing population.

\section{Ethics approval and consent to participate}

The study protocol was approved by the Institutional Review Board of the Peking University Health Science Centre, China, and College Research Ethics Committee of King's College London, UK. Written informed consent was obtained from all participants prior to study commencement. 


\section{Appendix A: Abbreviations}

\begin{tabular}{|c|c|}
\hline 8-OHdG & 8-Hydroxydeoxyguanosine \\
\hline AIC & Akaike information criterion \\
\hline AP & Augmentation pressure \\
\hline AIx & Augmentation index \\
\hline APHH & Air Pollution and Human Health programme \\
\hline $\mathrm{BC}$ & Black carbon \\
\hline BMI & Body mass index \\
\hline Chol & Total cholesterol \\
\hline $\mathrm{CO}$ & Carbon monoxide \\
\hline COPD & Chronic obstructive pulmonary disease \\
\hline CMCS & Chinese Multi-provincial Cohort Study \\
\hline CRP & C-reactive protein \\
\hline CVD & Cardiovascular disease \\
\hline DBP & Diastolic blood pressure \\
\hline DOW & Day of week \\
\hline EBC & Exhaled breath condensate \\
\hline $\mathrm{EC}$ & Elemental carbon \\
\hline ED & Ejection duration \\
\hline $\mathrm{FE}_{\mathrm{NO}}$ & Fractional exhaled NO \\
\hline GBD & Global Burden of Disease \\
\hline GC/MS & Gas chromatography-mass spectrometry \\
\hline HAP & Household air pollution \\
\hline HOMA-IR & Homeostatic model assessment of insulin resistance \\
\hline HDL & High-density lipoprotein \\
\hline IFN- $\gamma$ & Interferon gamma \\
\hline IL & Interleukin \\
\hline IAP & Institute of Atmospheric Physics \\
\hline INTERMAP & International Population Study on Macronutrients and BP \\
\hline LC/MS & Liquid chromatography-mass spectrometry \\
\hline LDL & Low-density lipoprotein \\
\hline MDA & Malondialdehyde \\
\hline NO & Nitrogen oxide \\
\hline $\mathrm{NO}_{2}$ & Nitrogen dioxide \\
\hline $\mathrm{O}_{3}$ & Ozone \\
\hline $\mathrm{OC}$ & Organic carbon \\
\hline PAHs & Polycyclic aromatic hydrocarbons \\
\hline PAM & Personal air monitors \\
\hline PEF & Peak expiratory flow \\
\hline PKU & Peking University \\
\hline $\mathrm{PM}_{1}$ & Particulate matter of aerodynamic diameter $\leq 1 \mu \mathrm{m}$ \\
\hline $\mathrm{PM}_{2.5}$ & Particulate matter of aerodynamic diameter $\leq 2.5 \mu \mathrm{m}$ \\
\hline $\mathrm{PM}_{10}$ & Particulate matter of aerodynamic diameter $\leq 10 \mu \mathrm{m}$ \\
\hline RH & Relative humidity \\
\hline SBP & Systolic blood pressure \\
\hline SEVR & Subendocardial viability ratio \\
\hline TG & Triglyceride \\
\hline $\mathrm{TNF} \alpha$ & Tumour necrosis factor alpha \\
\hline WBCs & White blood cells \\
\hline
\end{tabular}


Data availability. The datasets generated and/or analysed during the current study are not publicly available due to the requirements of the project but are available from the corresponding author on reasonable request.

Supplement. The supplement related to this article is available online at: https://doi.org/10.5194/acp-20-15775-2020-supplement.

Team list. Yiqun Han (BIC-ESAT and SKL-ESPC, College of Environmental Sciences and Engineering, Peking University, Beijing 100871, China; Environmental Research Group, MRC Centre for Environment and Health, Imperial College London, London, UK), $\mathrm{Wu}$ Chen (BIC-ESAT and SKL-ESPC, College of Environmental Sciences and Engineering, Peking University, Beijing 100871, China), Lia Chatzidiakou (Centre for Atmospheric Science, Department of Chemistry, University of Cambridge, Cambridge, UK), Li Yan (Environmental Research Group, MRC Centre for Environment and Health, Imperial College London, London, UK), Hanbin Zhang (Environmental Research Group, MRC Centre for Environment and Health, Imperial College London, London, UK), Yanwen Wang (BIC-ESAT and SKL-ESPC, College of Environmental Sciences and Engineering, Peking University, Beijing 100871, China), Yutong Cai (Environmental Research Group, MRC Centre for Environment and Health, Imperial College London, London, UK), Anika Krause (Centre for Atmospheric Science, Department of Chemistry, University of Cambridge, Cambridge, UK), Wuxiang Xie (Peking University Clinical Research Institute, Beijing, China), Yunfei Fan (BIC-ESAT and SKL-ESPC, College of Environmental Sciences and Engineering, Peking University, Beijing 100871, China), Teng Wang (BIC-ESAT and SKL-ESPC, College of Environmental Sciences and Engineering, Peking University, Beijing 100871, China), Xi Chen (BIC-ESAT and SKL-ESPC, College of Environmental Sciences and Engineering, Peking University, Beijing 100871, China), Tao Xue (BIC-ESAT and SKL-ESPC, College of Environmental Sciences and Engineering, Peking University, Beijing 100871, China), Gaoqiang Xie (Peking University Clinical Research Institute, Beijing, China), Yingruo Li (BIC-ESAT and SKL-ESPC, College of Environmental Sciences and Engineering, Peking University, Beijing 100871, China), Pengfei Liang (BIC-ESAT and SKL-ESPC, College of Environmental Sciences and Engineering, Peking University, Beijing 100871, China), Aoming Jin (Peking University Clinical Research Institute, Beijing, China), Yidan Zhu (Peking University Clinical Research Institute, Beijing, China), Yan Luo (Peking University Clinical Research Institute, Beijing, China), Xueyu Han (Department of Epidemiology, Beijing Anzhen Hospital, Capital Medical University, Beijing Institute of Heart, Lung and Blood Vessel Diseases, Beijing, China), Xinghua Qiu (BIC-ESAT and SKL-ESPC, College of Environmental Sciences and Engineering, Peking University, Beijing 100871, China), Queenie Chan (Environmental Research Group, MRC Centre for Environment and Health, Imperial College London, London; Department of Epidemiology and Biostatistics, MRC Centre for Environment and Health, Imperial College London, London, UK), Ben Barratt (Environmental Research Group, MRC Centre for Environment and Health, Imperial College London, London, UK), Majid Ezzati (Department of Epidemiology and Biostatistics, MRC Centre for Environment and Health, Imperial College London, Lon- don, UK), Paul Elliott (Department of Epidemiology and Biostatistics, MRC Centre for Environment and Health, Imperial College London, London, UK), Rod Jones (Centre for Atmospheric Science, Department of Chemistry, University of Cambridge, Cambridge, UK), Jing Liu (Department of Epidemiology, Beijing Anzhen Hospital, Capital Medical University, Beijing Institute of Heart, Lung and Blood Vessel Diseases, Beijing, China), Yangfeng Wu (Peking University Clinical Research Institute, Beijing, China; The George Institute for Global Health at Peking University Health Science Center, Beijing, China), Meiping Zhao (College of Chemistry, Peking University, Beijing, China), Junfeng Zhang (Duke Kunshan University, Nanjing, China), Frank J. Kelly (Environmental Research Group, MRC Centre for Environment and Health, Imperial College London, London, UK), Tong Zhu (BIC-ESAT and SKLESPC, College of Environmental Sciences and Engineering, Peking University, Beijing 100871, China).

Author contributions. All authors have disclosed that there are no actual or potential competing interests regarding the submitted article.

Competing interests. TZ and FK are co-principal investigators of AIRLESS, and they designed the study and revised the manuscript. YH participated in the study design, coordinated air pollution monitoring and clinical measurements at the Pinggu site, and drafted the manuscript. WC coordinated the clinical measurements at the PKU site. LC, AK, and RJ developed the personal monitor PAM and were involved in the monitor deployment and data ratification. $\mathrm{YH}, \mathrm{LY}$, $\mathrm{HZ}, \mathrm{XC}, \mathrm{YC}, \mathrm{WX}, \mathrm{AJ}, \mathrm{YZ}$, and YL are key staff who participated in the clinical measurements at the Pinggu site. WC, YW, TX, YF $\mathrm{XH}$, and TW are key staff who participated in the clinical measurements at the PKU site. $\mathrm{HZ}$ and $\mathrm{BB}$ participated in the residential air pollution measurement. $\mathrm{XQ}, \mathrm{MZ}$, and $\mathrm{JZ}$ were involved in the design of laboratory biomarkers. JL coordinated the CMCS cohort, and YL, XG, and QC coordinated the INTERMAP cohort. ME, PE, RJ, JL, MZ, JZ, and YW are co-investigators of the AIRLESS study and revised the manuscript. All authors read and approved the final version of the paper.

Special issue statement. This article is part of the special issue "In-depth study of air pollution sources and processes within Beijing and its surrounding region (APHH-Beijing) (ACP/AMT interjournal SI)". It is not associated with a conference.

Acknowledgements. We are greatly thankful to all the members of the AIRLESS team who helped to accomplish the fieldwork at the urban and peri-urban Beijing sites. We would also like to thank Roy Harrison and Zongbo Shi for organizing and coordinating the APHH programme. We also appreciate the AIRPOLL and AIRPRO study team for the collected data of ambient pollutants for reference calibration and further health analysis.

Financial support. This research has been supported by the National Natural Science Foundation of China (grant no. 
81571130100) and the Natural Environment Research Council of UK (grant nos. NE/N007018/1 and NE/S006729/1).

Review statement. This paper was edited by Pingqing Fu and reviewed by two anonymous referees.

\section{References}

Brook, R. D. and Rajagopalan, S.: Particulate matter, air pollution, and blood pressure, J. Am. Soc. Hypertens, 3, 332-350, https://doi.org/10.1016/j.jash.2009.08.005, 2009.

Brook, R. D., Rajagopalan, S., Pope, C. A.,, Brook, J. R., Bhatnagar, A., Diez-Roux, A. V., Holguin, F., Hong, Y., Luepker, R. V., Mittleman, M. A., Peters, A., Siscovick, D., Smith, S. C., Whitsel, L., and Kaufman, J. D.: Particulate matter air pollution and cardiovascular disease: An update to the scientific statement from the American Heart Association, Circulation, 121, 2331-2378, https://doi.org/10.1161/CIR.0b013e3181dbece1, 2010.

Brunekreef, B. and Holgate, S. T.: Air pollution and health, Lancet, 360, 1233-1242, https://doi.org/10.1016/S0140-6736(02)112748, 2002.

Burnett, R. T., Pope, C. A., Ezzati, M., Olives, C., Lim, S. S., Mehta, S., Shin, H. H., Singh, G., Hubbell, B., Brauer, M., Anderson, H. R., Smith, K. R., Balmes, J. R., Bruce, N. G., Kan, H. D., Laden, F., Pruss-Ustun, A., Michelle, C. T., Gapstur, S. M., Diver, W. R., and Cohen, A.: An Integrated Risk Function for Estimating the Global Burden of Disease Attributable to Ambient Fine Particulate Matter Exposure, Environ. Health Persp., 122, 397-403, https://doi.org/10.1289/ehp.1307049, 2014.

Carter, E., Yan, L., Fu, Y., Robinson, B., Kelly, F., Elliott, P., Wu, Y., Zhao, L., Ezzati, M., Yang, X., Chan, Q., and Baumgartner, J.: Household transitions to clean energy in a multiprovincial cohort study in China, Nature Sustainability, 3, 42-50, https://doi.org/10.1038/s41893-019-0432-x, 2020.

Liu, M., Lin, J., Boersma, K. F., Pinardi, G., Wang, Y., Chimot, J., Wagner, T., Xie, P., Eskes, H., Van Roozendael, M., Hendrick, F., Wang, P., Wang, T., Yan, Y., Chen, L., and Ni, R.: Improved aerosol correction for OMI tropospheric $\mathrm{NO}_{2}$ retrieval over East Asia: constraint from CALIOP aerosol vertical profile, Atmos. Meas. Tech., 12, 1-21, https://doi.org/10.5194/amt-12-1-2019, 2019.

Chatzidiakou, L., Krause, A., Han, Y., Chen, W., Yan, L., Popoola, O. A. M., Kellaway, M., Wu, Y., Liu, J., Hu, M., team, A., Barratt, B., Kelly, F. J., Zhu, T., and Jones, R. L.: Using low-cost sensor technologies and advanced computational methods to improve dose estimations in health panel studies: results of the AIRLESS project, J. Expo. Sci. Environ. Epidemiol., 30, 981-989, https://doi.org/10.1038/s41370-020-0259-6, 2020.

Dubowsky, S. D., Suh, H., Schwartz, J., Coull, B. A., and Gold, D. R.: Diabetes, obesity, and hypertension may enhance associations between air pollution and markers of systemic inflammation, Environ. Health Perspect., 114, 992-998, https://doi.org/10.1289/ehp.8469, 2006.

Dvonch, J. T., Kannan, S., Schulz, A. J., Keeler, G. J., Mentz, G., House, J., Benjamin, A., Max, P., Bard, R. L., and Brook, R. D.: Acute effects of ambient particulate matter on blood pressure: differential effects across urban communities, Hypertension, 53, 853-859, https://doi.org/10.1161/HYPERTENSIONAHA.108.123877, 2009.

Gao, Y., Chen, G., Tian, H., Lin, L., Lu, J., Weng, J., Jia, W., Ji, L., Xiao, J., Zhou, Z., Ran, X., Ren, Y., Chen, T., Yang, W., China National, D., and Metabolic Disorders Study, G.: Prevalence of hypertension in china: a cross-sectional study, PLoS One, 8, e65938, https://doi.org/10.1371/journal.pone.0065938, 2013.

Gong, J. C., Zhu, T., Kipen, H., Wang, G. F., Hu, M., Guo, Q. F., Ohman-Strickland, P., Lu, S. E., Wang, Y. D., Zhu, P., Rich, D. Q., Huang, W., and Zhang, J. F.: Comparisons of Ultrafine and Fine Particles in Their Associations with Biomarkers Reflecting Physiological Pathways, Environ. Sci. Technol., 48, 5264-5273, 2014.

Han, Y. Q. and Zhu, T.: Health effects of fine particles $\left(\mathrm{PM}_{2.5}\right)$ in ambient air, Sci. China Life Sci., 58, 624-626, 2015.

Han, Y. Q., Zhu, T., Guan, T. J., Zhu, Y., Liu, J., Ji, Y. F., Gao, S. N., Wang, F., Lu, H. M., and Huang, W.: Association between size-segregated particles in ambient air and acute respiratory inflammation, Sci. Total Environ., 565, 412-419, https://doi.org/10.1016/j.scitotenv.2016.04.196, 2016.

Huang, W., Zhu, T., Pan, X. C., Hu, M., Lu, S. E., Lin, Y., Wang, T., Zhang, Y. H., and Tang, X. Y.: Air Pollution and Autonomic and Vascular Dysfunction in Patients With Cardiovascular Disease: Interactions of Systemic Inflammation, Overweight, and Gender, American Journal of Epidemiology, 176, 117-126, 2012.

Jiang, H., Yan, W. H., Li, C. J., Wang, A. P., Dou, J. T., and Mu, Y. M.: Elevated White Blood Cell Count Is Associated with Higher Risk of Glucose Metabolism Disorders in Middle-Aged and Elderly Chinese People, Int. J. Env. Res. Pub. He., 11, 5497-5509, https://doi.org/10.3390/ijerph110505497, 2014.

Kelly, F. J. and Fussell, J. C.: Size, source and chemical composition as determinants of toxicity attributable to ambient particulate matter, Atmos. Environ., 60, 504-526, https://doi.org/10.1016/j.atmosenv.2012.06.039, 2012.

Kelly, F. J. and Zhu, T.: Transport solutions for cleaner air, Science, 352, 934-936, https://doi.org/10.1126/science.aaf3420, 2016.

Li, X. H., Song, J. C., Lin, T., Dixon, J., Zhang, G. Q., and Ye, H.: Urbanization and health in China, thinking at the national, local and individual levels, Environ. Health-Glob., 15, S32, https://doi.org/10.1186/s12940-016-0104-5, 2016.

Lin, W. W., Huang, W., Zhu, T., Hu, M., Brunekreef, B., Zhang, Y. H., Liu, X. G., Cheng, H., Gehring, U., Li, C. C., and Tang, X. Y.: Acute Respiratory Inflammation in Children and Black Carbon in Ambient Air before and during the 2008 Beijing Olympics, Environ. Health Persp., 119, 1507-1512, 2011.

Lin, W. W., Zhu, T., Xue, T., Peng, W., Brunekreef, B., Gehring, U., Huang, W., Hu, M., Zhang, Y. H., and Tang, X. Y.: Association Between Changes in Exposure to Air Pollution and Biomarkers of Oxidative Stress in Children Before and During the Beijing Olympics, American Journal of Epidemiology, 181, 575-583, 2015.

Liu, J., Hong, Y., D’Agostino, R. B., Sr., Wu, Z., Wang, W., Sun, J., Wilson, P. W., Kannel, W. B., and Zhao, D.: Predictive value for the Chinese population of the Framingham CHD risk assessment tool compared with the Chinese Multi-Provincial Cohort Study, JAMA, 291, 2591-2599, https://doi.org/10.1001/jama.291.21.2591, 2004. 
Liu, J., Han, Y. Q., Tang, X., Zhu, J., and Zhu, T.: Estimating adult mortality attributable to $\mathrm{PM}_{2.5}$ exposure in China with assimilated PM2.5 concentrations based on a ground monitoring network, Sci. Total Environ., 568, 1253-1262, https://doi.org/10.1016/j.scitotenv.2016.05.165, 2016.

Moore, E., Chatzidiakou, L., Jones, R. L., Smeeth, L., Beevers, S., Kelly, F. J., Quint, J. K., and Barratt, B.: Linking e-health records, patient-reported symptoms and environmental exposure data to characterise and model COPD exacerbations: protocol for the COPE study, BMJ Open, 6, e011330, https://doi.org/10.1136/bmjopen-2016-011330, 2016.

Parrish, D. D. and Zhu, T.: Climate change. Clean air for megacities, Science, 326, 674-675, https://doi.org/10.1126/science.1176064, 2009.

Rajagopalan, S. and Brook, R. D.: Air Pollution and Type 2 Diabetes Mechanistic Insights, Diabetes, 61, 3037-3045, https://doi.org/10.2337/db12-0190, 2012.

Sacks, J. D., Stanek, L. W., Luben, T. J., Johns, D. O., Buckley, B. J., Brown, J. S., and Ross, M.: Particulate matter-induced health effects: who is susceptible?, Environ. Health Perspect., 119, 446454, https://doi.org/10.1289/ehp.1002255, 2011.

Shah, A. S. V., Langrish, J. P., Nair, H., McAllister, D. A., Hunter, A. L., Donaldson, K., Newby, D. E., and Mills, N. L.: Global association of air pollution and heart failure: a systematic review and meta-analysis, Lancet, 382, 1039-1048, https://doi.org/10.1016/S0140-6736(13)60898-3, 2013.

Shi, Z., Vu, T., Kotthaus, S., Harrison, R. M., Grimmond, S., Yue, S., Zhu, T., Lee, J., Han, Y., Demuzere, M., Dunmore, R. E., Ren, L., Liu, D., Wang, Y., Wild, O., Allan, J., Acton, W. J., Barlow, J., Barratt, B., Beddows, D., Bloss, W. J., Calzolai, G., Carruthers, D., Carslaw, D. C., Chan, Q., Chatzidiakou, L., Chen, Y., Crilley, L., Coe, H., Dai, T., Doherty, R., Duan, F., Fu, P., Ge, B., Ge, M., Guan, D., Hamilton, J. F., He, K., Heal, M., Heard, D., Hewitt, C. N., Hollaway, M., Hu, M., Ji, D., Jiang, X., Jones, R., Kalberer, M., Kelly, F. J., Kramer, L., Langford, B., Lin, C., Lewis, A. C., Li, J., Li, W., Liu, H., Liu, J., Loh, M., Lu, K., Lucarelli, F., Mann, G., McFiggans, G., Miller, M. R., Mills, G., Monk, P., Nemitz, E., O'Connor, F., Ouyang, B., Palmer, P. I., Percival, C., Popoola, O., Reeves, C., Rickard, A. R., Shao, L., Shi, G., Spracklen, D., Stevenson, D., Sun, Y., Sun, Z., Tao, S., Tong, S., Wang, Q., Wang, W., Wang, X., Wang, X., Wang, Z., Wei, L., Whalley, L., Wu, X., Wu, Z., Xie, P., Yang, F., Zhang, Q., Zhang, Y., Zhang, Y., and Zheng, M.: Introduction to the special issue "In-depth study of air pollution sources and processes within Beijing and its surrounding region (APHH-Beijing)", Atmos. Chem. Phys., 19, 7519-7546, https://doi.org/10.5194/acp19-7519-2019, 2019.

Steinle, S., Reis, S., and Sabel, C. E.: Quantifying human exposure to air pollution-Moving from static monitoring to spatio-temporally resolved personal exposure assessment, Sci. Total Environ., 443, 184-193, https://doi.org/10.1016/j.scitotenv.2012.10.098, 2013.
Sun, Y. L., Wang, Z. F., Dong, H. B., Yang, T., Li, J., Pan, X. L., Chen, P., and Jayne, J. T.: Characterization of summer organic and inorganic aerosols in Beijing, China with an Aerosol Chemical Speciation Monitor, Atmos. Environ., 51, 250-259, https://doi.org/10.1016/j.atmosenv.2012.01.013, 2012.

Wang, Y. W., Han, Y. Q., Zhu, T., Li, W. J., and Zhang, H. Y.: A prospective study (SCOPE) comparing the cardiometabolic and respiratory effects of air pollution exposure on healthy and prediabetic individuals, Sci. China Life Sci., 61, 46-56, $2018 \mathrm{a}$.

Wang, Z. W., Chen, Z., Zhang, L. F., Wang, X., Hao, G., Zhang, Z. G., Shao, L., Tian, Y., Dong, Y., Zheng, C. Y., Wang, J. L., Zhu, M. L., Weintraub, W. S., Gao, R. L., and Investig, C. H. S.: Status of Hypertension in China Results From the China Hypertension Survey, 2012-2015, Circulation, 137, 2344-2356, https://doi.org/10.1161/Circulationaha.117.032380, 2018b.

WHO: Global, regional, and national comparative risk assessment of 84 behavioural, environmental and occupational, and metabolic risks or clusters of risks, 1990-2016: a systematic analysis for the Global Burden of Disease Study 2016, Lancet, 390, 1345-1422, https://doi.org/10.1016/S0140-6736(17)323668, 2017.

Wu, F., Xie, P., Li, A., Mou, F., Chen, H., Zhu, Y., Zhu, T., Liu, J., and Liu, W.: Investigations of temporal and spatial distribution of precursors $\mathrm{SO}_{2}$ and $\mathrm{NO}_{2}$ vertical columns in the North China Plain using mobile DOAS, Atmos. Chem. Phys., 18, 1535-1554, https://doi.org/10.5194/acp-18-1535-2018, 2018.

Xu, J., Zhang, X. L., Xu, X. F., Zhao, X. J., Meng, W., and Pu, W. W.: Measurement of surface ozone and its precursors in urban and rural sites in Beijing, Proced Earth Plan. Sc., 2, 255-261, https://doi.org/10.1016/j.proeps.2011.09.041, 2011.

Yan, L., Carter, E., Fu, Y., Guo, D., Huang, P., Xie, G., Xie, W., Zhu, Y., Kelly, F., Elliott, P., Zhao, L., Yang, X., Ezzati, M., Wu, Y., Baumgartner, J., and Chan, Q.: Study protocol: The INTERMAP China Prospective (ICP) study version 2; peer review: 1 approved, 1 approved with reservations, Wellcome Open Research, 4, https://doi.org/10.12688/wellcomeopenres.15470.2, 2020.

Yang, G. H., Wang, Y., Zeng, Y. X., Gao, G. F., Liang, X. F., Zhou, M. G., Wan, X., Yu, S. C., Jiang, Y. H., Naghavi, M., Vos, T., Wang, H. D., Lopez, A. D., and Murray, C. J. L.: Rapid health transition in China, 1990-2010: findings from the Global Burden of Disease Study 2010, Lancet, 381, 1987-2015, https://doi.org/10.1016/S0140-6736(13)61097-1, 2013.

Zhang, Y. L., Ma, Z. C., Lung, C. W., Sun, Y. N., and Li, X. H.: A New Approach for Assessment of Pulse Wave Velocity at Radial Artery in Young and MiddleAged Healthy Humans, J. Mech. Med. Biol., 12, 1250028, https://doi.org/10.1142/S0219519412500285, 2012.

Zhao, X. J., Zhang, X. L., Xu, X. F., Xu, J., Meng, W., and Pu, W. $\mathrm{W}$.: Seasonal and diurnal variations of ambient $\mathrm{PM}_{2.5}$ concentration in urban and rural environments in Beijing, Atmos. Environ., 43, 2893-2900, https://doi.org/10.1016/j.atmosenv.2009.03.009, 2009. 